\title{
Symbolism matters: The effect of same-sex marriage legalization on partnership stability
}

\author{
Shuai Chen ${ }^{\mathrm{a}, *}$, Jan C. van Ours ${ }^{\mathrm{b}, \mathrm{c}}$ \\ a Luxembourg Institute of Socio-Economic Research (LISER), Luxembourg \\ ${ }^{\mathrm{b}}$ Erasmus School of Economics, Rotterdam, the Netherlands; Department of Economics, University of Melbourne, Australia \\ ${ }^{\mathrm{c}}$ Tinbergen Institute (Rotterdam), CEPR (London) and IZA (Bonn)
}

\section{A R T I C L E I N F O}

\section{Article history:}

Received 7 May 2020

Revised 15 July 2020

Accepted 20 July 2020

Available online 2 August 2020

\section{JEL classification:}

D78

J12

J15

J16

K36

Keywords:

Same-sex marriage

Registered partnership

Separation

Duration analysis

\begin{abstract}
A B S T R A C T
Registered partnership (RP) and marriage in the Netherlands are identical in terms of rights and obligations but may differ in symbolism. Exploiting same-sex marriage legalization (SSML) in the Netherlands as a policy shock, we investigate the effect of marital symbolism on partnership stability. Applying a mixed competing risks model to administrative micro-data, we disentangle selectivity into marriage from the effect of getting married. Our main finding is that partnerships that transformed into marriage had a substantially lower separation rate. We take this result as evidence of the symbolic effect of marriage stabilizing partnerships. We discuss economic mechanisms of marital symbolism related to marriage premiums.
\end{abstract}

(C) 2020 The Author(s). Published by Elsevier B.V. This is an open access article under the CC BY license. (http://creativecommons.org/licenses/by/4.0/)

\section{Introduction}

In past decades, partnership formation and its economic functions have been changing. Formal relationships such as marriage have become less popular while informal relationships such as cohabitation have been on the rise. Formal relationships are also becoming more diverse. In addition to marriage, some countries have introduced a registered partnership (RP) which is similar to marriage though not always exactly the same. Partnership formation is transforming as well in the sense that same-sex RP has been introduced and same-sex marriage (SSM) has been legalized. The increased alternative types of partnerships to marriage are associated with the evolving role of marriage. Traditionally marriage provides couples with economic premiums in the way of production complementarities (Becker, 1991). Gradually, the sources of economic gains of marriage have switched to investment (Lundberg and Pollak, 2015) and consumption complementarities

\footnotetext{
The authors are grateful to reviewers as well as seminar participants at EBRD, Tilburg and LISER, and conference attendants at EEA/ESEM 2017, ENTER Jamboree 2017, ESPE 2017, Netherlands Economists Day 2017, Conference on Economics of Sexual Orientation 2019, and EALE 2019 for their helpful comments and suggestions on previous versions of this paper. The authors thank Statistics Netherlands (CBS) for making their restricted access micro-data available for analysis through a remote access facility.

* Corresponding author.

E-mail addresses: shuai.chen@liser.lu (S. Chen), vanours@ese.eur.nl (J.C. van Ours).
} 
(Stevenson and Wolfers, 2007). Marriage has evolved from a specialization device to a commitment mechanism (Delhommer and Hamermesh, 2020; Lundberg and Pollak, 2015).

Does this commitment mechanism of marriage affect marital stability? If so, what economic channels may explain this effect of marital commitment? This study explores these questions by extracting the symbolic significance of marriage as marital commitment. Marriage enforces a unique public commitment to a long-term and even lifelong relationship, which is usually expressed in front of families, relatives, friends and religious clans. This public commitment and its resulting enforceable trust reduce the transaction costs of enforcing agreements between the partners (Pollak, 1985). Furthermore, marriage has become a marker of individual prestige and personal achievement, rendering itself distinct from other types of relationships (Bulcroft et al., 2000). Finally, marital stability is important as it allows couples to enjoy the marriage premium over a longer period of time (Delhommer and Hamermesh, 2020; Hersch and Stratton, 2000).

After establishing RP in 1998, in 2001 the Netherlands was the first country to legalize SSM. ${ }^{1}$ In the Netherlands, RP and marriage are almost identical in terms of legal rights and obligations, regardless of sexual orientation (Trandafir, 2014). The main differences between them exist in their symbolic significance as well as divorce costs. We isolate marital symbolism by exploiting the plausibly exogenous symbolic variation induced by same-sex marriage legalization (SSML) in the Netherlands on same-sex RP. We use this policy change as a shock to marital symbolism to investigate the stability response of same-sex formal relationships i.e. marriage and RP. By examining transitions from RP to marriage and the corresponding improvement in stability, we estimate the effect of marital symbolism. Moreover, using a unique flash divorce arrangement in the Netherlands outside court with low expenses, we show that the higher divorce costs of marriage (than those of RP) are not the main driving force of the increased stability.

In many studies on the position of gay men and lesbians, sexual orientation is based on self-reporting. ${ }^{2}$ In our analysis, we use Dutch administrative micro-data where we identify the sexual orientation of every individual in a RP or marriage by comparing their gender with the gender of their partner. We apply a bivariate timing-of-events model to study transitions from a same-sex RP to marriage simultaneously with separations from RP. At the same time, we analyze whether a samesex partnership became more stable after being married. The mixed proportional hazard (MPH) specification of our model endows us with the capacity to make a distinction between two types of selectivity and "treatment". Selectivity may occur if inherently more stable RP are more likely to transform to marriage i.e. positive selection, or less likely to do so i.e. adverse selection. Alternatively, marriage may have a treatment effect, namely the effect of marital symbolism, if the transition from RP to marriage renders the existing partnership more stable. We take into account these two types of selection effects and different stability of partnerships by allowing both observables and unobservables to simultaneously affect the transition to marriage and separation. In the MPH model unobserved heterogeneity (UH) terms capture unobservables in the transitionto-marriage rate and in the separation hazard, respectively. These terms are able to account for potential selectivity of RP into marriage.

We find that indeed after being married, same-sex partnerships were less likely to dissolve. The symbolism of marriage had a stabilizing treatment effect on same-sex RP. This effect may be attributed to marriage premiums from two sources. First, marriage creates enhanced incentives to invest in tangible (e.g. property) or intangible (e.g. trust) assets. Second, marriage provides societal rewards to marrieds for the personal prestige or reputation they signal. ${ }^{3}$ These economic premiums induced by marital symbolism motivate couples to preserve their marriage longer. Moreover, we find that marriage had a stronger effect on partnerships of male same-sex couples than on female ones.

We detect a dominant adverse selection effect for male same-sex partnerships. Stable male same-sex RP were less likely to transform to marriage, while less stable ones were more inclined to do so probably to seek for the marriage premium. Female same-sex RP did not significantly present such a tendency. This gender heterogeneity in selectivity reflects the more sizable effect of marital symbolism among male same-sex partnerships.

We also document that SSML increased separation of pre-existing RP meanwhile initiating their transition to marriage. As mentioned above, such a transition to marriage took place mostly among unstable same-sex RP, especially for men. After this transition, marital symbolism stabilized the partnership. Furthermore, comparing the stability of SSM and same-sex RP formed post-legalization, we find that marriages were more stable. Therefore, even though in the short run SSML triggered separation of some pre-existing RP, in the long run it will stabilize the formal relationship market. This legislation will benefit the accumulation of marriage premiums.

In addition to the economic theories on various functions of marriage discussed at the beginning of this section, many recent studies in the economic literature of marital dynamics have focused on its direct economic incentives. For example, Persson (2020) investigates how Sweden's elimination of survivors insurance - an insurance provided through marriage contract - affected marital responses. She documents a reduction in marriage rate, an increase in divorce rate and an improvement in assortative matching correspondingly. In the same strand of research, only a handful of studies are on samesex partnerships. Zavodny (2008) explores whether the earning premium of married men also applies to cohabiting gay

\footnotetext{
1 Dee (2008) provides an early overview of same-sex partnership laws in Europe.

2 See for recent examples such as Powdthavee and Wooden (2015) who find that sexual minorities have lower levels of life satisfaction in the U.K. and Australia, Buser et al. (2018) who use Dutch data concluding that gay men compete less than straight men, whereas for women there is no difference in competitive behavior according to sexual orientation and Aksoy et al. (2019) who analyze U.K. data concluding that gay men are less likely than heterosexual men to be in high-level managerial positions.

${ }^{3}$ For instance, employers tend to employ married people (Daniel, 1995).
} 
men finding that this is not the case. A similar conclusion is drawn by Booth and Frank (2008). Oreffice (2011) estimates the effect of intra-household bargaining on gay men and lesbian couples' labor supply. She discovers a similar pattern of bargaining for same-sex (cohabiting) couples as for heterosexual cohabiting couples: younger or richer partners in samesex households have more bargaining power and supply less labor. This pattern is also established by Klawitter (2008). Badgett et al. (2008) analyze data collected among self-identified same-sex couples in California, before the state legalized SSM. They find limited economic motivations to register a partnership. ${ }^{4}$ Our paper contributes to this literature by examining marital reactions to the symbolic shock in marital commitment. Such responses of marital behaviors may be still interpreted in the economic sense. To the best of our knowledge, this study is the first to provide empirical evidence for the direct effect of marital symbolism.

The current study is also closely related to the literature on the stability of marriage and other relationships. Some previous studies compare the stability of non-married relationships between same-sex and different-sex couples and explore the reasons for their difference (Carpenter and Gates, 2008; Kurdek, 2004; Lau, 2012; Manning et al., 2016). The lower stability of same-sex non-married relationships may be related to their lower degree of household specialization, especially for females, compared to different-sex couples (Aldén et al., 2015). However, this specialization gap narrows across cohorts and different-sex and same-sex couples from recent cohorts have become similar (Giddings et al., 2014). Becker (1991) notes that "homosexual (non-married) unions are much less stable than heterosexual marriages" and that economic forces are responsible for this. Becker relates this to the higher search costs for homosexuals due to the "opprobrium attached to homosexuality" because of which, there is less information available making it harder to form stable relationships. Moreover, since same-sex non-married unions are less formalized, they dissolve at lower costs than different-sex marriages. Nevertheless, in a highly tolerant society like the Netherlands the homosexual opprobrium does not prevail. When same-sex and different-sex couples face the same formal marital institution, the difference in stability of their marriage may disappear. This conjecture is verified by our data (see Figure 3). We investigate the stability of formal relationships including RP and marriage for same-sex couples. The effect of marital symbolism estimated with these SSM thus may provide implications for different-sex marriages which lack a corresponding policy shock as SSML to cleanly identify the symbolic significance of marriage.

Our paper speaks to another economic literature of marriage on cultural norms and social attitudes. Bertrand et al. (2020) develop a model in which negative societal attitudes to working women contribute to the lower marriage rate of skilled women. With the same model they predict how this marriage gap will respond to labor market opportunities with variations in social attitudes to working women. They also verify their key predictions with data from the developed world. Folke and Rickne (2020) study how promotions to top political positions and CEO affect marital stability. They discover a rise in divorce hazard for women but not men and that divorces are mainly driven by gender-traditional couples. This suggests that the traditional gender career norm plays a vital role. In these studies, norms and attitudes are connected with understandings on marriage as a specialization device or production complementarities. However, our paper links marital norms and perceptions to symbolic commitment that is more relevant to investment and consumption complementarities as well as prestige and achievement markers. Furthermore, our findings that marital symbolism exerted a larger influence on male same-sex couples than female ones and that gay men registered partners presented stronger adverse selectivity into marriage to seek for marriage premiums go along with Badgett (2009). She argues that some feminist lesbian women might see marriage as a patriarchal institution, so marriage availability does not always stabilize partnerships especially for female same-sex couples. Thus such gender heterogeneity in perceptions of marital institution among same-sex couples may be associated with the gender differences in the effect size of marital symbolism and in the adverse selectivity mentioned above.

Finally, this study adds to the small but fast growing literature on the legislation of SSM. Recent studies find positive effects of SSML on employment (Sansone, 2019), investment induced marital surplus (Delhommer and Hamermesh, 2020) and health (Carpenter et al., 2018; Chen and van Ours, 2020) of same-sex couples, and on improvement in societal attitudes to sexual minorities (Aksoy et al., 2020). Influences of this policy change on marital behaviors have been examined among different-sex couples or traditional households (Dillender, 2014; Trandafir, 2014; 2015). No significant impacts are documented. Divergent from them, we investigate the marital reactions of same-sex couples - the direct target group of such a marital policy change. What is more, by focusing on pre-existing same-sex registered partners we are able to originally explore the effect of marital symbolism, a difference between marriage and RP in the Netherlands.

\section{Institutional background}

We study partnership dynamics in the Netherlands because its highly tolerant attitude to SSM and the equivalence of marriage and RP in legal benefits and responsibilities there facilitate our identification of the effect of marital symbolism. ${ }^{5}$ For example, in the Eurobarometer 2015, 91\% (the highest proportion among all the EU 28 countries) of the Dutch respon-

\footnotetext{
${ }^{4}$ Registered partnership in California was not equivalent to marriage as it was not portable across state lines and was not recognized by the federal government. Nevertheless, the Californian Supreme Court argued that marriage differs from a registered partnership not in its legal rights and responsibilities but only in its symbolic meaning and common understanding.

${ }^{5}$ In the Netherlands, homosexual acts were decriminalized in 1811 following the integration of the country into the French empire (in France decriminalization occurred in 1791; see Waaldijk (2001)). The cross-country variation in decriminalization of homosexual acts is huge. In England and Wales, sex
} 
dents agreed on the statement that "same sex marriages should be allowed throughout Europe", while the average across the 28 countries of the European Union was only 61\% (European Commission, 2015). In such an open-minded society and free atmosphere, compared to other countries, same-sex couples can enter and terminate a formal partnership with much less discrimination and external pressure. This kind of environment helps us to obtain a cleaner estimate of the effects of interest and might also make it possible to provide some implications for different-sex partnerships with our analysis.

As in many other countries, the Netherlands has experienced big changes in the partnership market. Marriages are declining while other types of relationships, including informal cohabitation and formal RP, have become popular. In this section we briefly present the evolution of RP and SSM in the Netherlands and discuss their similarities and differences. ${ }^{6}$

\subsection{Registered partnerships}

RP were introduced on January 1st, 1998 in the Netherlands. They have been open to both same-sex and different-sex couples since its initiation. Registered partners had many of the same rights and duties as married couples in, for instance, tax, property and inheritance. A RP was "almost a clone of marriage" (Waaldijk, 2001). Scherf (1999) provides information from a survey of recently established RP. Same-sex couples were asked whether they would have concluded a marriage if this had been a possibility with over $80 \%$ confirming that this would have been preferred. About $60 \%$ indicated that they would transform their RP to marriage should that become possible in the future. According to Scherf (1999) a RP had the same consequences as a marriage except when children were involved. In a marriage, the birth of a child automatically implies that both partners are parents. In a RP, only the biological mother was a parent in the eyes of the law whereas her partner was not considered as the other parent. Nevertheless, both partners could apply to court for joint custody of a child. On April 1st, 1998 the parenting law ended the privilege of married couples to adopt children. Since then, both individuals and couples in either a formal or an informal relationship regardless of their sexual orientation have been allowed to adopt a child. Thus in combination with this adoption law, the difference between marriage and RP in terms of children disappeared.

From April 1st, 2001 to March 1st, 2009, married couples in the Netherlands were permitted to switch their marriage to RP. This could be followed by a convenient and less costly divorce process without the need to go to court. ${ }^{7}$ Since it was not always recognized abroad as a divorce and lacked the legal arrangement for children born during the marriage, this so called flash divorce procedure was abolished on March 1st, 2009. In part of our analysis, we exploit these flash divorce policies to estimate the effect of divorce costs - around 750 euro including court fees and legal expenses (Government of the Netherlands, 2019; Teurlings Advocaten, 2019) and other non-monetary costs such as time invested related to court and legal arrangement for children - on partnership stability. By comparing this effect with that of marital symbolism, we throw light on the important role the latter plays in stabilizing formal relationships.

\subsection{Same-sex marriages}

Waaldijk (2001) provides a detailed description of the characteristics of the SSM law in the Netherlands. In August 1998 a newly formed Dutch government promised a same-sex marriage law. A draft of the law was introduced on July 8th, 1999. It passed by the Lower House on September 12th, 2000 and the Upper House on December 19th, 2000, and was signed into law on December 21st, 2000. The law came into force on April 1st, 2001. Since then "a marriage can be contracted by two persons of different sex or of the same sex" (Article 30 of Book 1 of the Dutch Civil Code). For the first time in human history, same-sex couples were officially and legally offered marriage equality.

Fig. 1 shows the annual numbers of new RP and marriages from 1998 to 2018. Panel a displays the development of samesex formal relationships. The solid line before 2001 combined with the lower dashed line denotes RP. The evolutions of the numbers of new RP and SSM are qualitatively very similar. In the first possible year, many new relationships are formalized. After it became possible to enter a RP or marriage, some couples were probably waiting for a while before they realized a new stage in their relationship. In the second and third year there is a decline in the numbers. From the fourth year onward the numbers fluctuate at a level of about 500 RP per year and about 1400 new SSM per year, in both cases with no clear upward or downward trend. Apparently, after 3-4 years a steady state in terms of new relationships is realized. We cannot rule out that up to the introduction of SSML some couples preferred not to enter a RP because they knew that SSM would be possible in the near future. Therefore, RP originating in the period 1998 to April 2001 could be different from those that started from April 2001 onward. We take this into account in our empirical analysis by doing separate estimates for the RP that started before April 2001 and those that started later.

Panel b of Fig. 1 illustrates the evolution of new different-sex RP and marriages. The different-sex couples present a different pattern. In 1998, approximately 90,000 marriages were formed. Up to 2001, RP was not very popular. With the

between two men was illegal until 1967 when it was decriminalized for men over 21 years of age. The decriminalization referred to "in private" meaning for example that men could not have sex in a hotel. A similar decriminalization was introduced in 1980 in Scotland and in 1982 in Northern Island.

${ }^{6}$ For legal details of RP and marriage we rely heavily on Waaldijk (2001).

7 From a research point of view, it is inconvenient that two different changes in marriage institutions, i.e. this flash divorce and same-sex marriage legalization, were introduced on the same day. Nevertheless, we are not concerned that this threatens the identification of our main effects of interest, i.e. the effect of SSML and the effect of marital symbolism. The flash divorce focused on the administrative process of transforming marriage to RP which was easier to dissolve. However, we study the first RP of individuals, which was not targeted by the flash divorce. Moreover, if registered partners chose to marry because of the option of flash divorce, this kind of selectivity would be captured by our MPH model. 
a. Same-sex

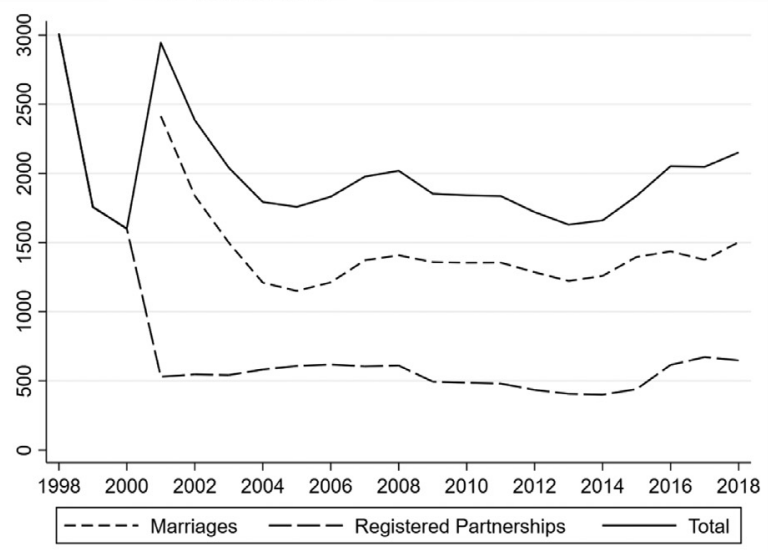

b. Different-sex

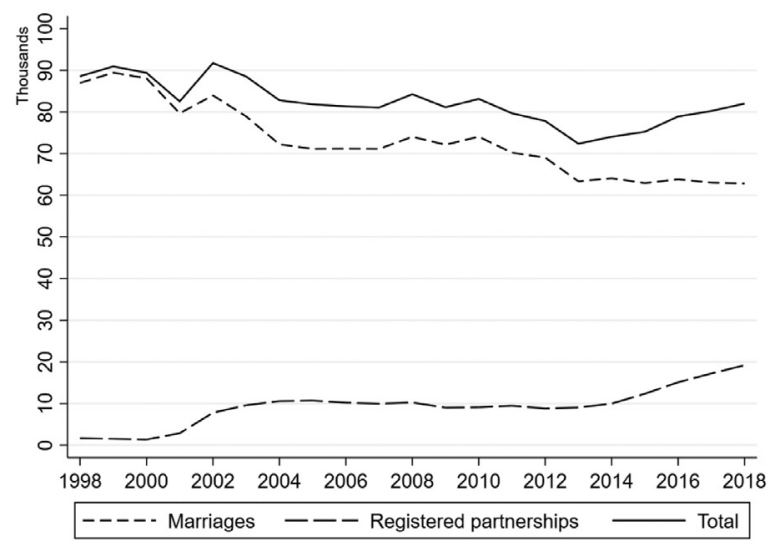

Fig. 1. New marriages and registered partnerships; 1998-2018 Source: Statistics Netherlands Note: The top line represents the total number of registered partnerships and marriages (for same-sex couples possible from 2001 onward). The middle line shows the number of marriages, the bottom line represents the number of registered partnerships.

initiation of the flash divorce in 2001, the number of new RP started to rise and then persisted at a level of around 10,000 per year from 2003 onward. Although at the beginning of the post-2001 period many RP occurred because of the transition from marriage, later on new RP not immediately following a marriage became dominant. After March 1st, 2009 due to the abolition of flash divorce, new entries into RP were not preceded by marriage any more.

Why would couples transform their RP to marriage? As discussed previously, there is not much difference between them in legal rights and responsibilities. A small difference between them is how the relationship legally starts and ends. People that want to marry have to declare "in the presence of the witnesses that they accept each other as husband and wife and that they will faithfully fulfill all duties which the law connects to their marital status" (Article 67 of Book 1 of the Dutch Civil Code). Registered partners formally start by registering through a registrar. A divorce of marriage can be obtained only in court. However, a RP can be dissolved through a contract if both partners consent and there are no minor children involved. If either of these two conditions is not met, the separation of a RP should be dealt with in court too. As we will show below in our empirical analysis on the flash divorce, divorce costs had a significant effect but could not explain the whole effect of the transition to marriage on marital stability. What still remains is the symbolic significance attached to marriage, i.e. the public commitment and the symbol of individual prestige and personal achievement. When both marriage and RP are options (after 2001 in panel a and all the years in panel b of Fig. 1), choosing to enter a marriage rather than RP may signal a strong public commitment and individual prestige. Fig. 1 displays that indeed many more new couples irrespective of sexual orientation preferred marriage to RP.

\section{Data}

In our study, we exploit rich administrative micro-data from Statistics Netherlands. The high quality individual level data include personal characteristics such as the country where the person was born, gender, immigrant status, birth year and month. There is also detailed information on every marital status of all individuals in the population, such as the beginning and ending dates, the birth year and month of the partner, the country where the partner was born, and the gender of the partner.

In order to make the data available for our study we had to address a number of issues. First, we identified the sexual orientation of every person by comparing their gender with the gender of their partner in every formal relationship, i.e. RP or marriage. Second, since the focus of our analysis is on the duration of formal relationships, we established the start date of every formal relationship and when applicable the end date. We also constructed some relationship characteristics such as the age difference between the two partners and whether the partners share the same origin, i.e. were born in the same country. Third, we gathered all, around 70,000, same-sex relationship records. In part of our study, we also investigate the stability of different-sex marriages. We randomly sampled the same number of different-sex marriages for comparison due to the highly demanding computational capacity of our model estimation. Finally, we followed only the first relationship of individuals to eliminate that the duration of one's later relationship was influenced by one's experiences of previous relationships. We traced every relationship for a maximum of 10 years until either their termination or the censoring time (death, widowhood, or end of data period) to make a comparison easier. In different parts of the analysis, we will discuss the different estimation samples used and provide the reason. The definitions and descriptives of the relevant variables in the baseline model are provided in Appendix A. There we find that most of the characteristics are significantly different between female and male same-sex couples. That is why we estimate the model separately by gender. On average female 
a. Two women; before (left) and after (right) the same-sex marriage law
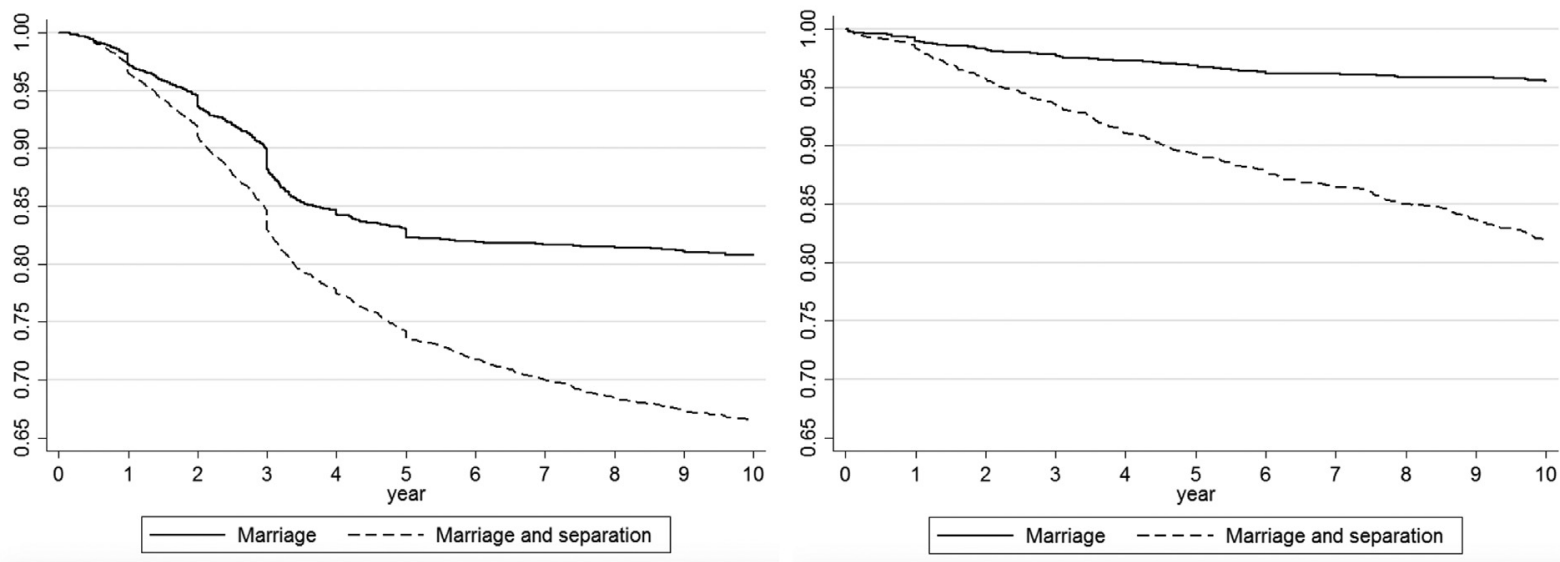

b. Two men; before (left) and after (right) the same-sex marriage law
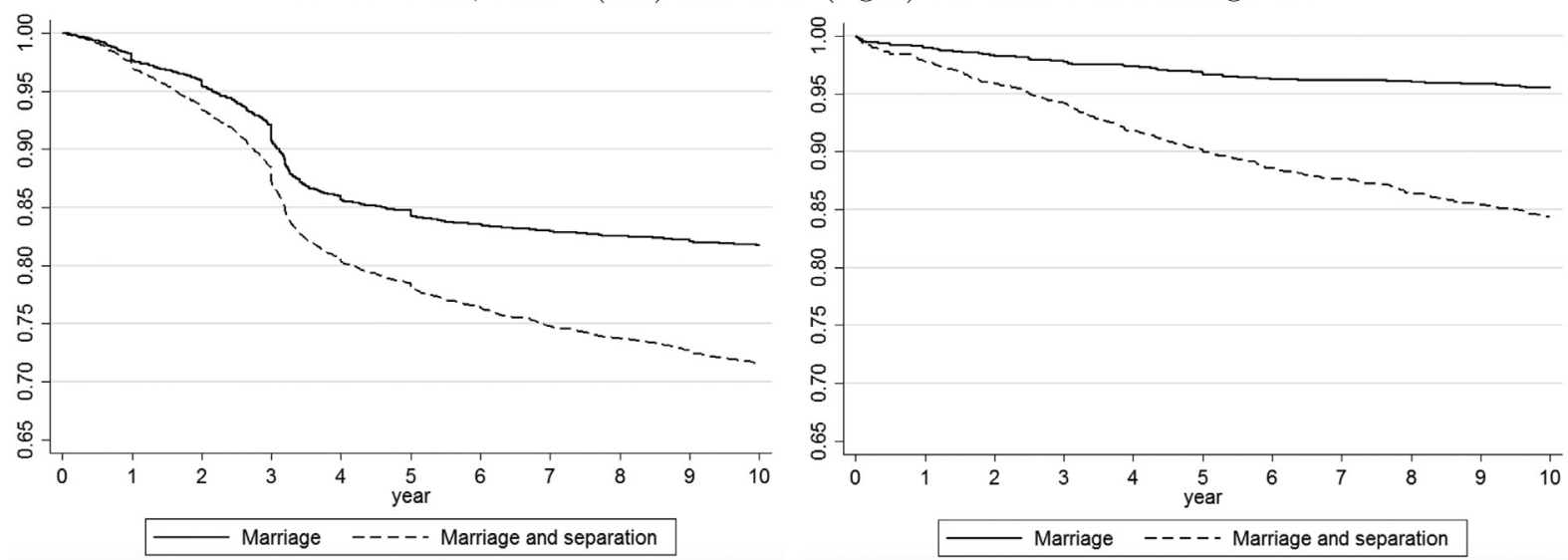

Fig. 2. Survival probabilities of same-sex registered partnerships that started before and after the introduction of the same-sex marriage law Note: The solid line indicates the transition from marriage to RP. The dashed line denotes the sum of the transitions from marriage to RP and to separation. After a $\mathrm{RP}$ transformed to marriage it is recorded in the solid line and censored, so the figure does not account for divorce from marriage.

same-sex couples have a smaller age difference and more children in their household than male ones. Moreover, a higher proportion of female same-sex couples is Dutch natives, has a partner with the same country of origin and entered their first $\mathrm{RP}$ before 40 years old than male couples. However, there is no significant gender difference in the duration of partnerships as long as they survived the first year.

To illustrate the nature of our data, we present survival functions of same-sex RP in Fig. 2. Panel a shows female samesex RP and panel b displays male ones. In both panels the left-hand side graphs present survival functions of RP that started before SSML. The right-hand side graphs do the same for RP established after this legislation. In each graph, the vertical distance between the solid line and the top scale 1.00 indicates the transformation to marriage from RP. The same distance from the dashed line to the top denotes the cumulative transitions from RP to marriage and direct separation. In another word, the vertical distance between the two lines illustrates the transition from RP to separation directly without marriage as an intermediate state. ${ }^{8}$ There is a clear difference between the left-hand side and right-hand side graphs. RP that started before SSML were less likely to survive. After 10 years, 20\% of them transformed to marriage and 10 (males) to 15\% (females) ended in direct separation. RP established after the legislation were as likely to directly separate but less likely to transform to marriage. This is no doubt related to the choice couples had to immediately go for a marriage rather than begin with a RP.

Figure 3 presents survival probabilities of same-sex and different-sex marriages that were established after SSML. The vertical distance from each line to the top denotes the probability of divorce in each corresponding group. During the first years of their existence different-sex marriages had the lowest divorce risk, but later they were less stable than male SSM.

\footnotetext{
${ }^{8}$ After a RP transformed to marriage it is recorded in the solid line and censored, so the figure does not account for divorce from marriage.
} 


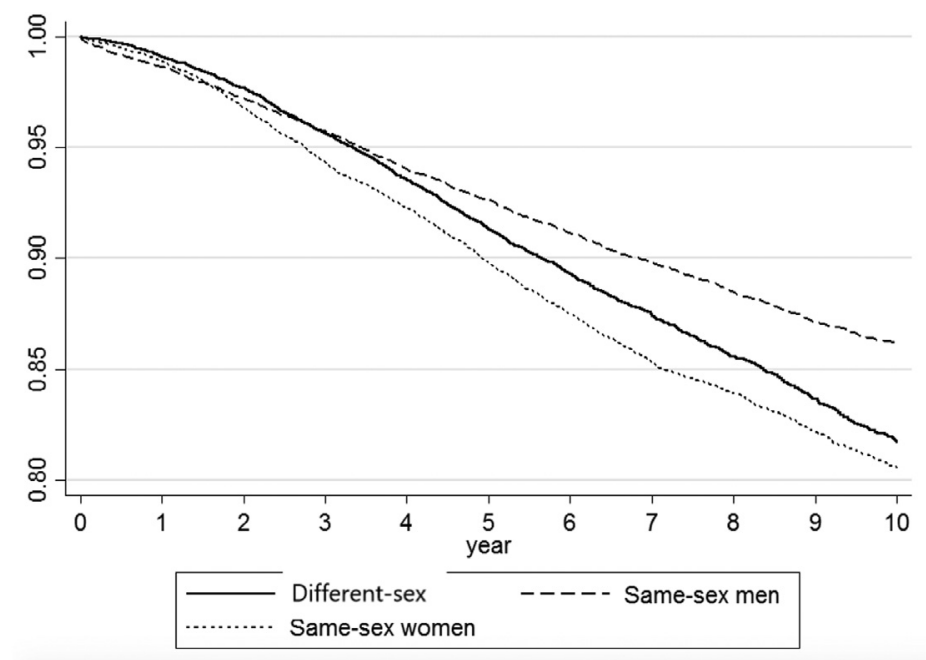

Fig. 3. Survival probabilities of marriages that started after same-sex marriage legalization.

Female SSM had the lowest survival probability, i.e. the highest divorce hazard, from the second year onward. Clearly, after SSML the marital stability of same-sex and different-sex couples in the Netherlands is not very different.

\section{Statistical model}

Farmer and Horowitz (2015) present a theoretical model in which same-sex couples follow a sequence in their relationship from dating via cohabitation to marriage. The last transition in their relationship may not occur if they live in a jurisdiction that prohibits SSM. Over time, partners gain information about the quality of their relationship and over the sequence of relationships both benefits and separation costs increase. Cohabiting same-sex couples can migrate to a jurisdiction that allows for SSM. Whether or not a cohabiting couple will migrate depends on the migration costs and the probability that in their current jurisdiction SSM will be legalized. If the probability for SSML increases, this may lead to relationship breakup if one partner desires to marry but the other prefers to remain cohabiting.

Following their model, we investigate the effect of SSML on the stability of same-sex RP. RP can terminate through either direct separation or the transformation to marriage (and then divorce). We are also interested in whether subsequent marriage is more or less stable than the preceding RP. To examine both effects, we use a bivariate timing-of-events approach simultaneously modeling the transition processes of RP to separation (direct or indirect through marriage) and to marriage. Marital symbolism may exert a treatment effect on the stability of same-sex RP. Therefore, we account for the possibility that after being married, the separation hazard changes. We begin our analysis with RP that were established before the legislation of SSM.

We model the transition rate from RP to marriage as follows. The marriage rate at duration $t$ conditional on a vector of observed characteristics $x$ and unobserved characteristics $v_{m}$ is specified as

$$
\theta_{m}\left(t \mid x, v_{m}\right)=\exp \left(x^{\prime} \beta_{m}+\Sigma_{k} \mu_{m k} I_{k}(t)+v_{m}\right) .
$$

The subscript $m$ denotes the transformation to marriage. Duration $t$ is measured in years that can be an integer or not. The vector $x$ includes the absolute age difference between the partners in a couple, whether the couple shares the country of origin, and whether the couple is native or the first or second generation immigrants. ${ }^{9}$ Furthermore, this vector also includes birth year cohorts, age cohorts of partnership entry, and partnership entry year dummies. ${ }^{10}$ The term $\Sigma_{k} \mu_{m k} I_{k}(t)$ represents piece-wise constant duration dependence, i.e. duration dependence that is constant in specific intervals where $k=$ $1,2, \ldots, K$ is the subscript for duration intervals and $I_{k}(t)$ are indicators which are equal to one in corresponding consecutive intervals. The true distribution of duration dependence can be arbitrarily closely approximated with a large number of duration intervals. We employ four duration intervals $(K=4 ; 0-1$ year, 1-3 years, 3-7 years, and longer than seven years)

\footnotetext{
${ }^{9}$ Unfortunately covariates such as income, labor market outcomes and educational attainment are not available from the population administrative microdata we use. However, we show in Table 10 that without controlling for any covariates except for starting year of partnership fixed effects, our estimates of parameters of interest are still robust. Therefore, such covariates may be important in explaining partnership stability, but absence of them is not expected to have a vital impact on the effects of SSML and of being married.

10 The inclusion of birth year, age of partnership entry and partnership entry year may generate a concern on the Age-Cohort-Time issue. Nonetheless, we aggregate birth year cohorts and age cohorts of partnership entry into bins of decades, so the collinearity problem does not exist in our model specification.
} 
and normalize $\mu_{1}=0$ for identification. ${ }^{11}$ Note that since a transition to marriage cannot take place before the legislation of SSM, the duration of a RP until its transition to marriage is counted from the date of legalization.

The conditional density function of a completed RP duration transitioning to marriage can be written as:

$$
f\left(t_{m} \mid x, v_{m}\right)=\theta_{m}\left(t_{m} \mid x, v_{m}\right) \exp \left(-\int_{0}^{t_{m}} \theta_{m}\left(s \mid x, v_{m}\right) d s\right)
$$

in which $t_{m}$ represents the duration of RP until it transformed to marriage.

Likewise, the separation hazard (either direct or indirect through marriage) of RP at time $t$ is as follows:

$$
\theta_{s}\left(t \mid x, I_{L}, I_{m}, v_{s}\right)=\exp \left(x^{\prime} \beta_{s}+\delta_{L} I_{L}+\delta_{m} I_{m}+\Sigma_{k} \mu_{s k} I_{k}(t)+v_{s}\right)
$$

Similarly, the subscript $s$ denotes separation. The vector $x$ contains the same observed characteristics and the pattern of duration dependence is the same as before. New elements in the specification of the separation rate are the two indicator variables. The first is $I_{L}=I\left(t>t_{L}\right)$, which denotes whether or not the duration of RP was beyond the legislation of SSM on April 1st, 2001. Although this is a fixed calendar date, RP started at different points in calendar time. Thus different couples passed the date of legalization at different durations of their RP. Therefore, we are able to distinguish this effect from duration dependence. The parameter $\delta_{L}$ captures the effect of SSML on the separation hazard. A positive $\delta_{L}$ would indicate that the legalization raised the separation rate possibly due to disagreement between the partners on the next phase of their relationship, i.e. marriage (Badgett, 2009; Farmer and Horowitz, 2015). A negative $\delta_{L}$ would represent a stabilizing effect of SSML. The second indicator variable in the separation hazard is $I_{m}=I\left(t>t_{m}\right)$ which denotes whether a RP got married. The parameter $\delta_{m}$ identifies the change in the separation risk after being married. A negative $\delta_{m}$ would imply that marriage induced the preceding RP to become more stable with its symbolic significance; a positive $\delta_{m}$ would refer to that marriage was less stable than the preceding RP.

The conditional density function of a completed RP duration ending with separation can be written as:

$$
f\left(t_{s} \mid x, I_{L}, I_{m}, v_{s}\right)=\theta_{s}\left(t_{s} \mid x, I_{L}, I_{m}, v_{s}\right) \exp \left(-\int_{0}^{t_{s}} \theta_{s}\left(t \mid x, I_{L}, I_{m}, v_{s}\right) d t\right)
$$

where $t_{s}$ denotes the duration of RP until it dissolved either directly or through marriage. In our analysis it is important to account for potential selectivity in the transition from RP to marriage. RP that transformed to marriage may be different for unobserved reasons from those that were not. ${ }^{12}$ It could be that more stable RP switched to marriage while less stable ones dissolved. If this were the case and we failed to take such a positive selection into account, we might wrongly interpret a significant negative estimate of $\delta_{m}$ as the treatment effect, i.e. the stabilizing effect of marital symbolism. Nevertheless, it could be also that less stable registered partners selected themselves into marriage for the sake of marriage premiums induced by marital commitment and symbolism. If we did not account for such an adverse selection, we would underestimate the true effect of the symbolism of marriage. To disentangle the two types of selection effects from the treatment effect of marital symbolism, we model the transitions from RP to separation and to marriage simultaneously and allow the two corresponding unobserved heterogeneity (UH) components $v_{s}$ and $v_{m}$ to be correlated. These two components represent common unobserved time-invariant confounding factors.

The joint conditional density function of a completed duration of RP that end with either separation or marriage can be specified as

$$
f\left(t_{m}, t_{s} \mid x, I_{L}, I_{m}\right)=\int_{v_{m}} \int_{v_{s}} f\left(t_{s} \mid x, I_{L}, I_{m}, v_{s}\right) f\left(t_{m} \mid x, v_{m}\right) d G\left(v_{s}, v_{m}\right)
$$

in which $G\left(v_{s}, v_{m}\right)$ is the joint discrete distribution of the two UH components each of which is supposed to take two values. ${ }^{13}$ Because we estimate constants too, we normalize $v_{s 1}=v_{m 1}=0$. The associated probabilities are

$$
\begin{array}{ll}
p_{1}=\operatorname{Prob}\left(v_{s}=v_{s 1}, v_{m}=v_{m 1}\right) & p_{2}=\operatorname{Prob}\left(v_{s}=v_{s 2}, v_{m}=v_{m 1}\right) \\
p_{3}=\operatorname{Prob}\left(v_{s}=v_{s 1}, v_{m}=v_{m 2}\right) & p_{4}=\operatorname{Prob}\left(v_{s}=v_{s 2}, v_{m}=v_{m 2}\right)
\end{array}
$$

where $p_{j}$ is assumed to follow a multinomial logit distribution: $p_{j}=\frac{\exp \left(\alpha_{j}\right)}{\sum_{j} \exp \left(\alpha_{j}\right)}$, in which $\alpha_{j}$ is a set of parameters, for $j=1, \ldots, 4$ with $\alpha_{4}$ normalized to zero. We use this multinomial logit distribution only to guarantee positive values of the probabilities, but we do not rely on it for our fundamental identification. Since both the separation hazard and the transition rate to marriage are assumed to have two types, in combination there may be four types. Modeling the selection effects,

\footnotetext{
11 In Table 9 of Appendix C we conduct a sensitivity analysis by changing k to 3 or 5 and obtain virtually identical results.

12 In Appendix A we present the descriptives of observables by gender and by whether the RP transformed to marriage. For both female and male samesex couples, on average the age difference, number of children in the household, the proportion of having a partner with the same country of origin and immigration status are not very different between RP that transformed to marriage and those that did not. However, registered partners that entered marriage were more likely to be born after 1962, i.e. younger than 39 when SSM was legalized, and maintained their relationship longer than those that did not get married. Specifically among female couples, compared to RP that did not transform to marriage, RP that later did so were established when the couple was younger. We do not find this pattern among male same-sex couples.

13 We could have had more than two values for each UH component. However, in the estimation the data does not support the assumption of more diverse groups than two in each of the separation hazard and transition-to-marriage rate.
} 
these two sets of UH are able to capture some important elements of a relationship such as preferences of a couple and quality of the relationship. A combination of easy separation and easy marriage indicates an impulsive couple that is usually in a low quality relationship, or a couple seeking for marriage premiums; a combination of low separation and difficult marriage refers to a cautious type. Both of these represent adverse selection. The remaining two combinations imply types with positive selection - RP with low separation risk more likely transform to marriage and unstable RP have a low marriage rate. Eq. (5) is used as basis for our log-likelihood function that is maximized over all parameters. We perform separate estimations for male and female same-sex couples.

A major advantage of utilizing this kind of timing-of-events model is that, as shown by Abbring and van den Berg (2003), identification of the treatment effect does not rely on a conditional independence assumption and it is not necessary to have a valid instrumental variable to establish the causal effect. Instead, identification comes from the timing of events, namely the order in which separations and transformations to marriage occurred. ${ }^{14}$ To establish whether one event has a causal effect on the hazard of the other event, the key identification assumption is no-anticipation. This assumption imposes a recursive structure on the underlying process. No-anticipation does not imply that forward-looking individuals cannot have an expectation on possible future events. As long as they do not act on this expectation by changing outcomes, the noanticipation assumption is not violated (Abbring and van den Berg, 2003). In the context of our analysis, individuals may have exact plans about the event that matters here, i.e. about their date of future marriage. The question is whether and how they will respond in anticipation to that future event. It does not seem very likely that because of the event planned they are more likely to separate. Partnerships breaking up in anticipation of a planned marriage are rare. It does seem probable that partnerships are less likely to split up in anticipation of a marriage. If under the no-anticipation assumption we analyze that getting married diminishes the separation rate, we actually underestimate this stabilizing effect of marriage since the partnership before marriage has already become more stable due to anticipation of marriage. Likewise, if we establish that getting married raises the separation rate, we overestimate this marital effect. Moreover, if a RP dissolves because one partner proposes marriage while the other does not want it and hence decides to separate, this has been taken into account in our model investigating the direct effect of SSML, i.e. captured by $\delta_{L}{ }^{15}$ Identification also relies on the mixed proportional structure of the separation hazard and transition rate to marriage. We use a very flexible specification of the hazard rates as we do not impose functional form assumptions on age dependence or on the distributions of UH in the hazards of marriage and separation.

\section{Parameter estimates}

\subsection{Duration of same-sex partnerships}

Table 1 provides an overview of the main parameter estimates based on same-sex RP that were formed before SSML, namely from Jan. 1st, 1998 to Apr. 1 st, 2001. ${ }^{16}$ Panel a reports results of the competing risks version of the model where the two sets of UH are correlated. That is to say, this model specification accounts for potential selectivity of RP into marriage. Panel b displays outcomes of the single risk version that ignores the correlation between the UH thus potential selectivity.

Our main interest is twofold. First, we explore the effect of SSML on the separation hazard. Second, we want to know whether or not being married stabilized its preceding RP. Although the magnitudes of both effects are larger for male partnerships than for female ones, our main findings are similar. In panel a, the SSML increased the separation rate by almost $50 \%(\exp (0.39)-1)$ for female partnerships (column 1) and about $200 \%(\exp (1.11)-1)$ for male partnerships (column 3$)$. Moreover, RP that transformed to marriage were more stable than before. Being married reduced the separation hazard by $68 \%(1-\exp (-1.13))$ for female partnerships (column 1) and $98 \%(1-\exp (-3.72)$ ) for male ones (column 3 ). Both effects are significantly different from zero. As discussed in the previous section, in the light of the possible absence of no-anticipation these estimated effects of marriage could be a lower bound of the treatment effects, i.e. the true stabilizing effect of marriage on partnerships may be larger than our estimates.

We also find positive duration dependence in the separation hazard in column 1 and 3 . Note that the coefficient of the omitted reference category $0-1$ year is normalized to zero. After their first year, RP were more likely to dissolve. In later years, the separation rate did not change much. In column 2 and 4, the transition rate from RP to marriage shows a strong negative duration dependence (again, the estimate of the category $0-1$ year is normalized to zero). In the first year after SSML, the marriage rate was high. In later years the transition rate was substantially lower.

The estimated distribution of UH in panel a is presented at the bottom of the table. We can identify three combinations of separation hazards and marriage rates. There is no group which conditional on observed characteristics and duration dependence has a low separation hazard and a high marriage rate. ${ }^{17}$ As mentioned before, the correlation between the two

\footnotetext{
14 This identification strategy has been adopted in Van den Berg et al. (2004), Abbring et al. (2005), Tatsiramos (2009) and so forth, and its previous parametric version had been applied by Lillard (1993) and Lillard and Panis (1996) in the context of marriage, fertility, health and mortality.

15 As a sensitivity analysis to further alleviate concerns on anticipation effects, we employ a sub-sample in which we discard RP that were established between one quarter before and one quarter after SSML. The parameter estimates are very similar.

16 All parameter estimates are presented in Appendix B.

17 The associated probability of the group which has a low separation hazard and a high marriage rate converges to zero. A low separation rate signals a stable partnership. For these partnerships there is no urgent need to transform to marriage. Hence for this group the marriage rate is low across the board.
} 
Table 1

Parameter estimates transition rates of same-sex registered partnerships to marriage and separation (either directly or through marriage as an intermediate state).

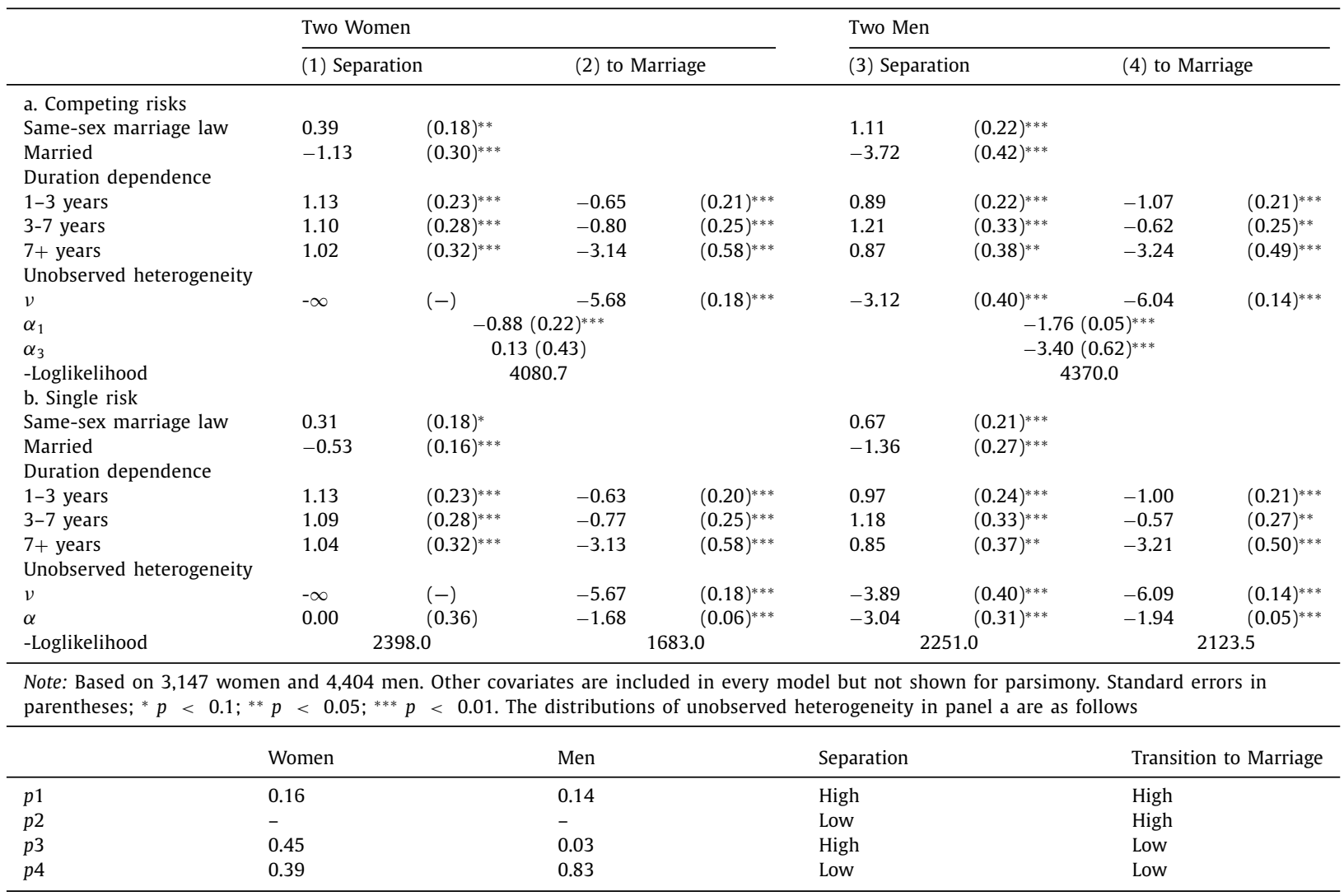

sets of UH captures two types of selectivity. On the one hand, positive selection refers to that stable RP (low separation hazard) are more likely to transform to marriage (high marriage rate), or that less stable RP (high separation hazard) are less inclined to transform to marriage (low marriage rate). On the other hand, adverse selection means that stable RP (low separation hazard) are less likely to transform to marriage (low marriage rate), or that less stable RP (high separation hazard) are more inclined to transform to marriage (high marriage rate). For both females and males, the probability of adverse selection $\left(p_{1}+p_{4}\right)$ is greater than that of positive selection $\left(p_{2}+p_{3}\right)$. Thus adverse selection dominates positive selection in the transition from RP to marriage, especially for males. The main difference between females and males is that the largest group for males is the one that has low transition rates to both separation and marriage whereas for females there is also a substantial group with a combination of low transition rate to marriage and high separation hazard.

Panel b of Table 1 shows the relevant parameter estimates if we do not take into account the correlation between the UH components of the two transition rates. The results for female same-sex couples are similar to those in panel a. ${ }^{18}$ Therefore, statistically we cannot reject the hypothesis that there is no correlation between the UH components. For male same-sex partnerships the difference between the competing risks and single risk estimates is significant. ${ }^{19}$ Apparently, adverse selection is an issue for male same-sex RP.

How can we interpret our main findings? For registered partners that made the transition to marriage, their relationship became more stable. Note that according to our estimates this is not due to the selection effect such that more stable RP transformed to marriage. It is even the other way around. Especially more stable male same-sex RP were less inclined to transform to marriage, while female same-sex RP did not present significant selectivity into marriage. Providing that marriage and RP are equivalent in legal functions in the Netherlands, we attribute this stabilizing treatment effect of marriage to marital symbolism and higher divorce costs of marriage. The public commitment and its resulting enforceable trust in-

For partnerships with a high separation rate, there are two types: one impulsive type very likely to transform to marriage, the other type not very likely to make this transition.

${ }_{18}$ The absolute sum of the log-likelihoods in column 1 and 2 of panel b is 4081.0, which is almost identical to the minus log-likelihood of the joint estimate in panel a that has a value of 4080.7 .

${ }^{19}$ The absolute sum of the log-likelihoods in column 3 and 4 of panel b is 4374.5 and in panel a it is 4370.0 . The value of the Likelihood Ratio test equals 9.0, which with one degree of freedom is significantly different from zero. 
Table 2

Parameter estimates separation rates from same-sex relationships (both registered partnerships and marriages) starting after the same-sex marriage law.

\begin{tabular}{|c|c|c|c|c|}
\hline \multirow[b]{2}{*}{ Married } & \multicolumn{2}{|c|}{ (1) Two women } & \multicolumn{2}{|c|}{ (2) Two men } \\
\hline & -0.55 & $(0.13)^{* * *}$ & -1.00 & $(0.16)^{* * *}$ \\
\hline \multicolumn{5}{|c|}{ Duration dependence } \\
\hline $1-3$ years & 1.33 & $(0.20)^{* * * *}$ & 0.85 & $(0.20)^{* * *}$ \\
\hline $3-7$ years & 1.56 & $(0.27)^{* * *}$ & 1.27 & $(0.26)^{* * * *}$ \\
\hline $7+$ years & 1.49 & $(0.57)^{* * *}$ & 0.89 & $(0.66)$ \\
\hline \multicolumn{5}{|c|}{ Unobserved heterogeneity } \\
\hline$v$ & -2.16 & $(0.95)^{* *}$ & -3.42 & $(0.60)^{* * *}$ \\
\hline$\alpha$ & -2.01 & $(1.57)$ & -1.67 & $(0.84)^{* *}$ \\
\hline -Loglikelihood & \multicolumn{2}{|c|}{2169.3} & \multicolumn{2}{|c|}{1681.6} \\
\hline Observations & \multicolumn{2}{|c|}{9,061} & \multicolumn{2}{|c|}{11,069} \\
\hline
\end{tabular}

Note: All covariates and constant in previous models are included in every model but not shown for parsimony. Both columns use the first marriage or registered partnership of every individual that started after the law and are right censored at the flash divorce ban; standard errors in parentheses; ${ }^{*} p<0.1$; ** $p<0.05 ;{ }^{* * *} p<0.01$

duced by marital symbolism encourage same-sex couples to invest higher levels of tangible and intangible capitals in their marriage. Society also rewards marrieds for the personal prestige or reputation they signal through marriage. ${ }^{20}$ For instance, employers prefer married employees (Daniel, 1995). These marriage premiums from marital symbolism improve partnership stability. If marital symbolism exerts influence through this economic mechanism, we will expect that fragile RP tend to marry in order to seek for marriage premiums. Our estimates indeed reflect this channel: symbolic significance of marriage had a stronger positive treatment effect on male same-sex RP than female ones; less stable RP selected into marriage, a phenomenon presented more significantly among male same-sex couples than female ones.

Why are there gender differences in the effect size of marital symbolism and selectivity among same-sex registered partners? Gender heterogeneity of sexual minorities has been rarely analyzed in the literature. Among the limited number of studies, Badgett (2009) discusses that the perception of marriage as a patriarchal institution by some feminist lesbians could impair the positive marital impacts. This kind of marital attitude and understanding will shrink the beneficial effect of marital symbolism and the corresponding marriage premiums to some extent among lesbian women. Moreover, even though Sansone (2019) documents that SSML raised the probability of employment for both gay men and lesbian women couples, Hansen et al. (2019) find that this legislation reduced the annual labor supply measured with paid work hours for lesbian women but not gay men. If so, female same-sex couples on average may obtain smaller economic surplus than male ones. Thus, even if lesbian women appreciate the symbolic significance of marriage too, they may invest less economically in marriage than gay men. Delhommer and Hamermesh (2020) find significant marriage surplus due to investment only among married gay men couples but not their lesbian women counterparts. Therefore, in order to enjoy these marriage premiums, unstable gay men registered partners transformed to marriage while lesbian women did not significantly present this adverse selectivity.

Our estimated effect of SSML on the stability of same-sex partnerships verifies the prediction of Farmer and Horowitz (2015)'s theoretical model: after the legislation one partner wanted to marry while the other preferred to keep the current RP; the disagreement between them on future marital arrangement may have induced a dissolution of their RP. Escalation to a more advanced relationship requires agreement. When through legalization, marriage becomes an option for same-sex couples, the costs of marriage entry drop. Thus, there are two possibilities for low quality same-sex RP. First, one but not both partners passes a threshold in his or her utility function. So one partner prefers to enter a marriage while the other partner prefers to stay in the RP. This induces conflicts increasing the separation rate, which is captured by our parameter estimate of SSML. The second possibility is that both partners in a low quality RP pass their marriage threshold in their utility function and hence agree to marry. However, the essence of their marriage, its inherent low quality, determines the separation in the future. This is reflected in the adverse selection captured by the correlated UH in our model.

Table 2 confirms that SSM were more stable than same-sex RP. It presents parameter estimates using a sample of the first marriages and RP that started between SSML and flash divorce abolition. These first partnerships are tracked until the abolition of flash divorce for estimation convenience. A RP was censored at the time when it transformed to marriage. As shown in the table, the separation risk of marriages was significantly lower than that of RP (omitted reference group). In this setting without a policy shock and a bivariate MPH structure, we are unable to disentangle the selectivity of RP into marriage from the stabilizing effect of marital symbolism. Instead, we simply compare these first marriages and RP established post-SSML and provide descriptive evidence that the former are more stable.

\footnotetext{
${ }^{20}$ Although we cannot directly relate it to SSML, the Eurobarometer indeed shows improved attitudes in the Netherlands towards sexual minorities after SSML. In the wave of 1997 pre-SSML, the proportions of being in favor of the right of sexual minorities to get married and to adopt children were $85.3 \%$ and $70.3 \%$, respectively. In 2001 post-SSML, these percentages rose to $90.0 \%$ and $74.3 \%$, respectively.
} 
Table 3

Parameter estimates effects of flash divorce on separation rates from marriages.

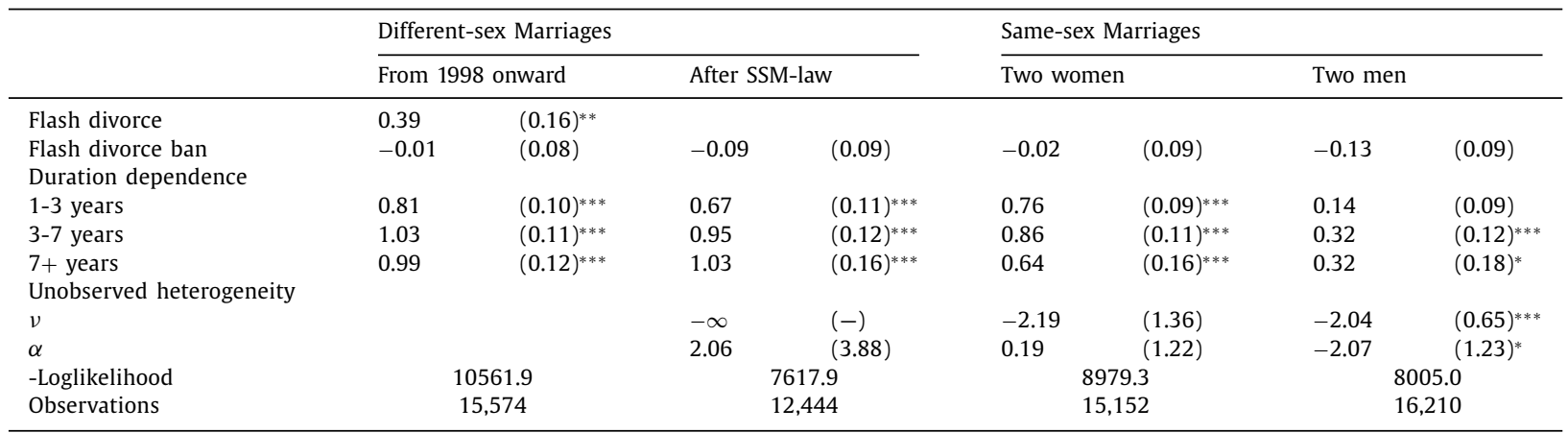

Note: All covariates and constant in previous models are included in every model but not shown for parsimony. Column (1) shows the estimates for different-sex marriages starting from 1998 onward; columns (2) to (4) contain marriages that were set up after the introduction of same-sex marriage and flash divorce. Standard errors in parentheses; ${ }^{*} p<0.1 ;{ }^{* *} p<0.05 ;{ }^{* * *} p<0.01$

\subsection{Flash divorce and duration of marriages}

In this subsection, we exploit flash divorce policies to explore the effect of higher divorce costs of marriage on partnership stability and also provide bounds for it. The result based on different-sex marriages here may suggest that divorce costs do not account for the whole stabilizing effect of being married identified in the previous subsection. ${ }^{21}$

From April 1st, 2001 to March 1st, 2009, both different-sex and same-sex married couples could terminate their marriage through a convenient and less costly process, the so called flash divorce. These couples first changed their marital status to RP. Then they chose whether to end the RP or not without going to court. By divorcing through this special procedure, it may save up to around 750 euro legal fees and other non-monetary costs such as time invested related to court and legal arrangement for children. We use the flash divorce to analyze how divorce costs affected the separation hazard of differentsex marriages. The effect of flash divorce cannot be identified for SSM since this type of marriages did not exist before April 1st, 2001. The model specification is slightly adjusted based on Eq. (3). The separation rate of marriages is defined as:

$$
\theta_{s}\left(t \mid x, I_{F D}, I_{B F D}, v_{s}\right)=\exp \left(x^{\prime} \beta_{s}+\delta_{F D} I\left(t>t_{F D}\right)+\delta_{B F D} I\left(t>t_{B F D}\right)+\Sigma_{k} \mu_{k} I_{k}(t)+v_{s}\right)
$$

in which the indicator variables $I_{F D}$ and $I_{B F D}$ denote the time of the introduction and abolition of flash divorce. Furthermore, $\delta_{F D}$ captures the effect of initiating flash divorce and $\delta_{B F D}$ is the effect of abolishing it. The density function of a completed duration of marriage, i.e. the duration until a separation took place can be written as:

$$
f_{s}\left(t \mid x, I_{F D}, I_{B F D}, v_{s}\right)=\theta_{s}\left(t_{m} \mid x, I_{F D}, I_{B F D}, v_{s}\right) \exp \left(-\int_{0}^{t_{s}} \theta_{s}\left(t \mid x, I_{F D}, I_{B F D}, v_{s}\right) d t\right) .
$$

We remove the UH by integration

$$
f_{s}\left(t \mid x, I_{F D}, I_{B F D}\right)=\int_{v_{s}} f_{s}\left(t_{s} \mid x, I_{F D}, I_{B F D}, v_{s}\right) d H\left(v_{s}\right)
$$

where $H\left(v_{s}\right)$ is the distribution of $\mathrm{UH}$ which we assume to be discrete with two points of support following a logistic distribution.

The estimation sample of different-sex marriages consists of the first marriage of different-sex couples established between 1998 and 2015 to be comparable with same-sex formal relationships that did not exist until 1998. Column (1) of Table 3 displays parameter estimates of this full sample. ${ }^{22}$ The introduction of flash divorce significantly raised the separation hazard of different-sex married couples by $48 \%(\exp (0.39)-1)$. Quite a few different-sex couples who got married between January 1st, 1998 and April 1st, 2001, took advantage of this convenient divorce procedure to end their marriage after this procedure was available.

The flash divorce procedure was abolished on March 1st, 2009. After this date the divorce costs of marriage rose to the pre-flash divorce level. In the first column of Table 3 the flash divorce ban had an insignificant effect on the divorce rate

\footnotetext{
${ }^{21}$ There may be a concern with the extrapolation of the estimate based on different-sex marriages to SSM. Different-sex and same-sex couples from recent cohorts have become similar (Giddings et al., 2014), let alone in the highly tolerant Dutch society for sexual minorities. A remarkable difference between them based on our data is the likelihood of children in the household. Different-sex married couples have a considerably higher probability of having children at home than same-sex married couples. Thus the effect of divorce costs on marital stability is larger for different-sex marrieds than for same-sex ones in that the divorce costs include monetary and non-monetary parts related to children. By applying the larger estimated effect of divorce costs of different-sex couples to same-sex couples, the remaining effect of marital symbolism will be underestimated. That is to say, we provide a lower bound for the effect of marital symbolism on partnership stability.

${ }^{22}$ We estimated a version with UH but both $v$ and $\alpha$ were very imprecisely estimated. Also, the LR test did not reject the version reported. The complete estimation results of Table 3 are presented in Appendix B.
} 
Table 4

Sensitivity analysis heterogeneous separation rates of same-sex registered partnerships.

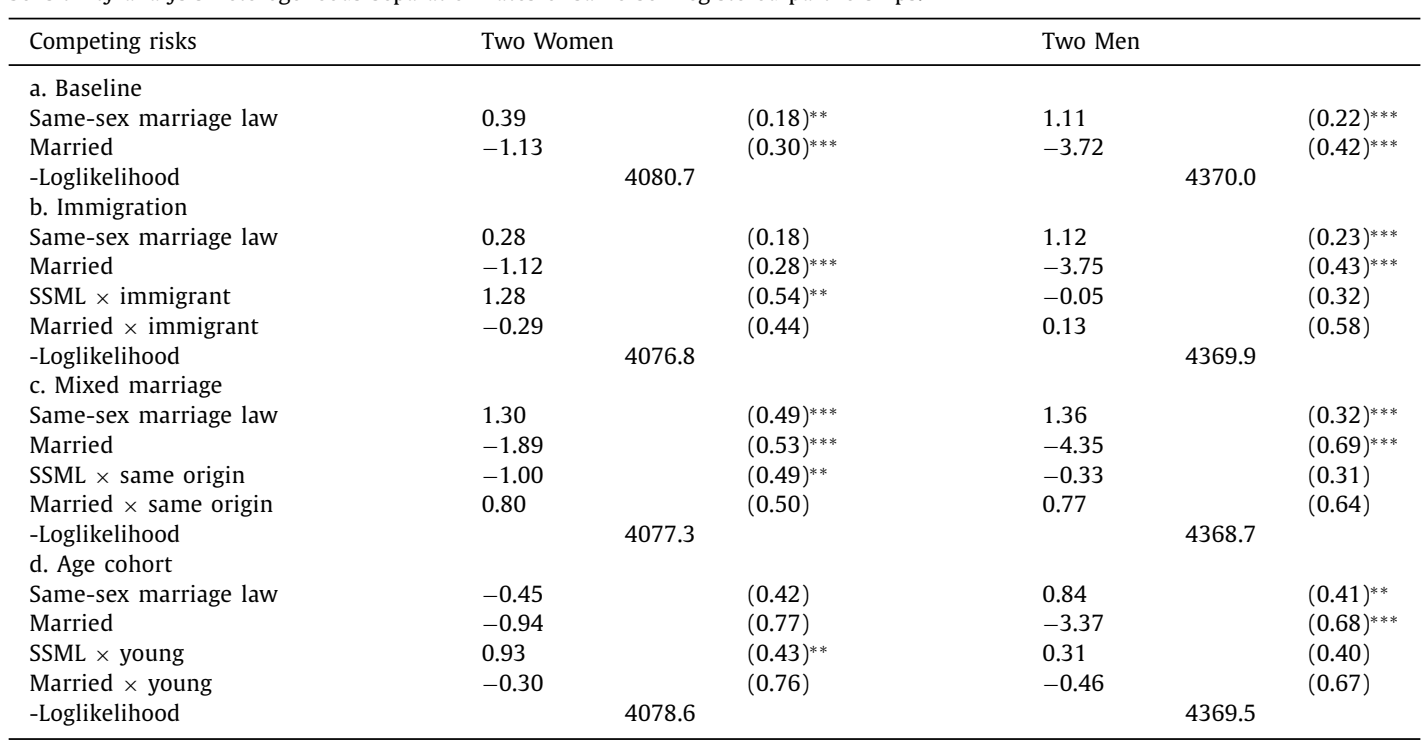

Note: Based on 3,147 women and 4,404 men. The parameter estimates presented in panel a are identical to those of panel a in Table 1 . Standard errors in parentheses; ${ }^{* *} p<0.05 ;{ }^{* * *} p<0.01$.

of different-sex couples, which was due to the gradual decline in separation between the flash divorce introduction and its abolition. The second column reports parameter estimates for different-sex marriages that started after the introduction of flash divorce (SSM too). Also for them, the effect of flash divorce abolition was not significantly different from zero. Estimates for SSM are displayed in the third and fourth columns. For these marriages, the flash divorce ban had no significant effect on the separation rate either. This result provides a lower bound of the effect of divorce costs on partnership stability. Subtracting this estimate from the effect of being married, we also obtain an upper bound of the effect of marital symbolism.

One of the issues that remain is the importance of children. Children may be a vital factor influencing a couple's decision of whether or not to separate. However, children will not be a big concern in our main analysis since the sample consists of the first RP only. The vast majority of same-sex couples ( $81 \%$ for females and $99 \%$ for males) did not have a child at home. ${ }^{23}$ Still, we used information about the number of children in the household in another dataset (household administrative data) and added it to our baseline model. The main parameter estimates shown in Appendix C are hardly affected.

\subsection{Heterogeneity investigation}

In this subsection we examine heterogeneities in terms of immigration, mixed marriages and age cohorts. We are interested in which subgroups are the main driving force of the effects of SSML and being married on partnership stability.

Table 4 displays the results. For ease of comparison panel a replicates the baseline estimates of Table 1. Panel b shows the divergent effects between natives and immigrants. The first two rows report the effects on separation rates of SSML and of being married for native Dutch people. They are rather close to the baseline estimates although the effect of the legalization for female same-sex couples loses its significance. The two interaction terms present the additive effects for immigrants. The additive effect of SSML is significant and in a much larger magnitude among female sexual minority immigrants. However, the additive effect of being married is not significant for female immigrants and neither of the additive effects for male immigrants are significant. Thus for female sexual minorities, SSML increased the separation hazard mainly among immigrants while the stabilizing effect of marriage was present for both natives and immigrants. For male sexual minorities, there are no significant differences in either effect between natives and immigrants.

In panel c we pay attention to whether intra-household cultural differences have an impact on the effects of SSML and being married. We additionally interact the two main variables of interest with a dummy variable indicating whether the couple shares the same country of origin. For both female and male same-sex couples with different countries of origin i.e. mixed marriages, the effects of SSML and of being married are larger in absolute terms than their counterparts in the baseline model. Nevertheless, the additive effect of the legalization is significantly negative for female couples sharing the same origin and it almost neutralizes the common SSML effect in the first row. Hence the effect of the legalization for female couples was mainly driven by those in a mixed marriage. Post-SSML, the disagreement on the future marital arrangement

\footnotetext{
${ }^{23}$ In the descriptives table of Appendix A, the average number of children is 0.31 in the household of lesbian women couples and 0.01 in that of gay men couples.
} 
more likely occurred between partners in a mixed marriage and resulted in their separation. The additive effect of being married is not significant for female couples sharing the same origin. Moreover, there are no significant differences in these effects between male couples sharing the same origin and those in a mixed marriage.

Finally, we want to know whether there is heterogeneity according to age cohort. In panel $\mathrm{d}$ we interact the dummies of the post-SSML period and of being married with a dummy variable indicating the younger cohort consisting of individuals born after 1952, i.e. those younger than 49 when the SSM was legalized in 2001. For female same-sex couples, the common effect of SSML becomes negative and the common effect of being married loses its significance. Nonetheless, the additive effect of the legalization for the younger cohort is significantly positive and the additive effect of being married is further (insignificantly) negative. So the effect of SSML in the baseline model previously was mainly dominated by the younger cohort and the stabilizing effect of marriage was also stronger among younger people. For male same-sex couples, the two effects are qualitatively similar to the baseline estimates though they are both in a larger magnitude (insignificantly) in the younger cohort.

All in all, among female same-sex couples, the negative SSML effect on partnership stability was mainly driven by immigrants, partners with different countries of origin and the younger cohort; getting married stabilized the partnership regardless of the immigration status or mixed marriage but this impact was stronger in the younger cohort. Among male same-sex couples, none of the included interaction effects are significantly different from zero suggesting that there is no significant heterogeneity in the main parameters according to the immigration status, mixed marriage or age cohort.

\section{Conclusions}

It is not clear whether the symbolic meaning of a marriage contributes to the stability of the relationship. Partners can decide to marry or not to marry and it could be that the stability of a marriage is driven by selectivity, i.e. partnerships that are inherently more stable are more likely to transform into a marriage. For a long time it was not possible for same-sex individuals to enter a formal partnership. In the past decades this situation has changed in many countries. Initially, samesex individuals were permitted to enter a RP, later on they were provided with marriage equality. This change in marriage institutions allows us to study the effect of marital symbolism on the stability of partnerships. In the Netherlands, since 1998 same-sex individuals have been able to legally register their partnership. From April 2001 onward they can be married to a same-sex spouse. We exploit the introduction of the same-sex marriage (SSM) in the Netherlands as a policy shock that added marital symbolism to existing RP. Knowing whether this symbolism affects partnership stability is important also from an economic point of view. The stabilizing effect of marital symbolism may manifest through two economic mechanisms: first, martial commitment induces couples to invest higher levels of capitals; second, society rewards married people for the personal prestige they signal. These marriage premiums help to improve marital stability.

Opening up the possibility for same-sex couples to transform their RP to marriage does not necessarily imply that this is the only possible response. It may be also that the reduced costs of marriage entry due to SSML have different impacts on the utility function of two partners of the couple: one partner passes its threshold of marriage while the other does not or at least not immediately. Such a disagreement could indicate that the introduction of SSM stimulated separation from some RP.

We study how the Dutch SSML affected the stability of same-sex RP. We find that SSML indeed caused quite a few RP to separate. Nevertheless, many other RP transformed to marriage. We also investigate whether marriage that consecutively followed RP was more stable than it originally was. In theory, marriage could be more stable because of positive selection as mentioned above. Using a bivariate hazard rate model with marriage and separation as competing risks and allowing the transformation to marriage to directly affect the separation rate, we find that for females selectivity is not a serious issue while for males there is significant adverse selection. Apparently, male same-sex RP that were less likely to dissolve were also less likely to transform to marriage while less stable male same-sex RP were more inclined to transform to marriage probably for marriage premiums. Female same-sex RP did not significantly present such adverse selection in that some feminist lesbian women could regard marriage as a patriarchal institution rather than an improved marital commitment and that female same-sex couples enjoyed less marriage premiums than male ones.

For both females and males, we find a strong and significant effect of getting married on their partnership stability though the effect is more sizeable for male same-sex couples. Once turned into marriage, relationships were much more stable than they were before as RP. Studying the effects of the flash divorce policies on marriage duration, we conclude that the divorce costs cannot explain the whole stabilizing effect of marriage on partnership stability. This is all the more surprising since the main remaining difference between RP and marriage seems to be merely symbolic. Apparently, the symbolism of marriage has a powerful stabilizing effect on interpersonal relationships. Marital symbolism may exert influence through marriage premiums owing to intra-household investment and societal reward.

\section{Declaration of Competing Interest}

The authors declare that they have no known competing financial interests or personal relationships that could have appeared to influence the work reported in this paper. 


\section{Supplementary material}

\section{Supplementary material associated with this article can be found, in the online version, at 10.1016/j.jebo.2020.07.021.}

\section{References}

Abbring, J.H., van den Berg, G.J., 2003. The nonparametric identification of treatment effects in duration models. Econometrica 71 (5), $1491-1517$.

Abbring, J.H., van den Berg, G.J., van Ours, J.C., 2005. The effect of unemployment insurance sanctions on the transition rate from unemployment to employment. Econ. J. 115 (505), 602-630.

Aksoy, C.G., Carpenter, C.S., De Haas, R., Tran, K., 2020. Do laws shape attitudes? Evidence from same-sex relationship recognition policies in Europe. Eur. Econ. Rev. 124 (103399), 1-18.

Aksoy, C.G., Carpenter, C.S., Frank, J., Huffman, M.L., 2019. Gay glass ceilings: sexual orientation and workplace authority in the UK. J. Econ. Behav. Organ. 159, 167-180.

Aldén, L., Edlund, L., Hammarstedt, M., Mueller-Smith, M., 2015. Effect of registered partnership on labor earnings and fertility for same-sex couples: evidence from Swedish register data. Demography 52 (4), 1243-1268.

Badgett, M., Gates, G.J., Maisel, N.C., 2008. Registered domestic partnerships among gay men and lesbians: the role of economic factors. Rev. Econ. Household 6 (4), 327-346.

Badgett, M.L., 2009. When Gay People Get Married: What Happens When Societies Legalize Same-Sex Marriage. NYU Press, NY.

Becker, G.S., 1991. A Treatise on the Family. Harvard University Press, Cambridge, MA.

Bertrand, M., Cortés, P., Olivetti, C., Pan, J., 2020. Social norms, labor market opportunities, and the marriage market penalty for skilled women. Rev. Econ. Stud. conditionally accepted.

Booth, A.L., Frank, J., 2008. Marriage, partnership and sexual orientation: a study of British university academics and administrators. Rev. Econ. Household 6 (4), 409-422.

Bulcroft, R., Bulcroft, K., Bradley, K., Simpson, C., 2000. The management and production of risk in romantic relationships: a postmodern paradox. J. Fam. Hist. 25 (1), 63-92.

Buser, T., Geijtenbeek, L., Plug, E., 2018. Sexual orientation, competitiveness and income. J. Econ. Behav. Organ. 151, 191-198.

Carpenter, C., Eppink, S.T., Gonzales Jr, G., McKay, T., 2018. Effects of access to legal same-sex marriage on marriage and health: evidence from BRFSS. NBER Working Paper No. 24651.

Carpenter, C., Gates, G.J., 2008. Gay and lesbian partnership: evidence from California. Demography 45 (3), $573-590$.

Chen, S., van Ours, J.C., 2020. Mental health effects of same-sex marriage legalization. mimeo.

Daniel, K., 1995. The marriage premium. In: Tommasi, M., Ierulli, K. (Eds.), The New Economics of Human Behavior. Cambridge University Press, pp. 113-125.

Dee, T.S., 2008. Forsaking all others? The effects of same-sex partnership laws on risky sex. Econ. J. 118 (530), 1055-1078.

Delhommer, S., Hamermesh, D.S., 2020. Same-sex couples and the marital surplus: the importance of the legal environment. J. Policy Anal. Manage. forthcoming.

Dillender, M., 2014. The death of marriage? The effects of new forms of legal recognition on marriage rates in the United States. Demography 51 (2), 563-585.

European Commission, 2015. Discrimination in the EU in 2015; Special Eurobarometer 437. European Union.

Farmer, A., Horowitz, A.W., 2015. Same-sex relationship escalation with uncertain marriage legality: theory and empirical implications. South. Econ. J. 81 (4), 995-1011.

Folke, O., Rickne, J., 2020. All the single ladies: job promotions and the durability of marriage. Am. Econ. J.-Appl. Econ. 12 (1), $260-287$.

Giddings, L., Nunley, J.M., Schneebaum, A., Zietz, J., 2014. Birth cohort and the specialization gap between same-sex and different-sex couples. Demography 51 (2), 509-534.

Government of the Netherlands, 2019. Arranging a divorce, legal separation or termination of a registered partnership. http://www.government. nltopicsdivorce-separation-and-termination-of-registered-partnership/divorce-legal-separation-or-termination-of-a-registered-partnership.

Hansen, M.E., Martell, M.E., Roncolato, L., 2019. A labor of love: the impact of same-sex marriage on labor supply. Rev. Econ. Household 18, 265-283.

Hersch, J., Stratton, L.S., 2000. Household specialization and the male marriage wage premium. ILR Rev. 54 (1), 78-94.

Klawitter, M., 2008. The effects of sexual orientation and marital status on how couples hold their money. Rev. Econ. Household 6 (4), $423-446$.

Kurdek, L.A., 2004. Are gay and lesbian cohabiting couples really different from heterosexual married couples? J. Marriage Fam. 66 (4), 880-900.

Lau, C.Q., 2012. The stability of same-sex cohabitation, different-sex cohabitation, and marriage. J. Marriage Fam. 74 (5), 973-988.

Lillard, L.A., 1993. Simultaneous equations for hazards: marriage duration and fertility timing. J. Econom. 56 (1-2), $189-217$.

Lillard, L.A., Panis, C.W., 1996. Marital status and mortality: the role of health. Demography 33 (3), $313-327$.

Lundberg, S., Pollak, R.A., 2015. The evolving role of marriage: 1950-2010. Future Child. 25 (2), 29-50.

Manning, W.D., Brown, S.L., Stykes, J.B., 2016. Same-sex and different-sex cohabiting couple relationship stability. Demography 53 (4), $937-953$.

Oreffice, S., 2011. Sexual orientation and household decision making: same-sex couples' balance of power and labor supply choices. Lab. Econ. 18 (2), $145-158$.

Persson, P., 2020. Social insurance and the marriage market. J. Polit. Econ. 128 (1), 252-300.

Pollak, R.A., 1985. A transaction cost approach to families and households. J. Econ. Lit. 23 (2), 581-608.

Powdthavee, N., Wooden, M., 2015. Life satisfaction and sexual minorities: evidence from Australia and the United Kingdom. J. Econ. Behav. Organ. 116, $107-126$.

Sansone, D., 2019. Pink work: same-sex marriage, employment and discrimination. J. Public Econ. 180, 104086.

Scherf, Y., 1999. Registered Partnership in the Netherlands; a quick scan. Van Dijk, Van Someren and Partners, Amsterdam.

Stevenson, B., Wolfers, J., 2007. Marriage and divorce: changes and their driving forces. J. Econ. Perspect. 21 (2), $27-52$.

Tatsiramos, K., 2009. Unemployment insurance in Europe: unemployment duration and subsequent employment stability. J. Eur. Econ. Assoc. 7 (6), $1225-1260$.

Teurlings Advocaten, 2019. Cost divorce. http://www.teurlingsadvocaten.nl.

Trandafir, M., 2014. The effect of same-sex marriage laws on different-sex marriage: evidence from the Netherlands. Demography 51 (1), 317-340.

Trandafir, M., 2015. Legal recognition of same-sex couples and family formation. Demography 52 (1), $113-151$.

Van den Berg, G.J., van der Klaauw, B., van Ours, J.C., 2004. Punitive sanctions and the transition rate from welfare to work. J. Lab. Econ. 22 (1), $211-241$.

Waaldijk, C., 2001. Small change: how the road to same-sex marriage got paved in the Netherlands. In: Wintemute, R., Audenæs, M. (Eds.), Legal Recognition

of Same-Sex Partnerships; A Study of National, European and International Law. Oxford and Portland: Hart Publishing, pp. 437-464.

Zavodny, M., 2008. Is there a 'marriage premium' for gay men? Rev. Econ. Household 6 (4), 369-389. 